\title{
Sumatriptan-Induced Growth Hormone Release in Patients with Major Depression, Mania, and Normal Controls
}

\author{
Lakshmi N. Yatham, M.B.B.S., F.R.C.P.C, M.R.C.Psych (UK), D.P.M., \\ Athanasios P. Zis, M.D., F.R.C.P.C., Raymond W. Lam, M.D., F.R.C.P.C., \\ Edwin Tam, M.D., F.R.C.P.C., and I-Shin Shiah, M.D.
}

The purpose of this study was to assess serotonergic function in patients with major depression or mania using sumatriptan, a novel 5-HT1D receptor agonist, as a pharmacological probe in a neuroendocrine challenge paradigm. We studied 18 drug free patients ( 10 with acute unipolar major depression and 8 with acute mania) who met DSM-IV criteria, and healthy controls. Subjects presented for testing after an overnight fast. After obtaining a blood sample for baseline growth hormone $(\mathrm{GH})$ levels, sumatriptan $(6 \mathrm{mg})$ was given subcutaneously, and further blood samples were collected at half hour intervals for 2 hours. The results showed that GH responses to sumatriptan were blunted in depressed patients but not in manics, compared to healthy controls. There were no differences in basal $G H$ levels between the 3 groups. The results of this study provide further support for the role of serotonergic system in pathophysiology of major depression, but not in mania. [Neuropsychopharmacology 17:258-263, 1997] (C) 1997 American College of Neuropsychopharmacology. Published by Elsevier Science Inc.
KEY WORDS: Sumatriptan; Major depression; Mania; 5-HT1D receptors; Growth hormone

Hormonal responses to challenges with various pharmacological probes provide a simple, dynamic, in vivo means of assessing central neurotransmitter function in humans (Yatham and Steiner 1993). This paradigm has been widely used to assess central serotonin (5-hydroxytryptamine, 5-HT) function in major depression, and the studies have in general provided evidence for 5-HT dysfunction in this condition. For instance, several investigations have shown blunted prolactin and/or corti-

From the Division of Mood Disorders, Department of Psychiatry, The University of British Columbia, Vancouver, Canada.

Address correspondence to: Lakshmi N. Yatham, Asst Professor in Psychiatry, Director, Mood Disorders Clinical Research Unit, The University of British Columbia, 2255 Wesbrook Mall, Vancouver, BC, Canada V6T 2A1.

Received August 15, 1996; revised March 12, 1997; accepted March 27, 1997. sol responses to challenges with L-tryptophan (Cowen and Charig 1987), clomipramine (Golden et al. 1992), fenfluramine (O'Keane and Dinan 1992), and ipsapirone (Lesch et al. 1990) in patients with major depression compared to healthy controls. In contrast, only three studies, to date, used this approach to assess 5-HT function in acute mania (Meltzer et al. 1984; Yatham 1994; Yatham 1996). In part, this may reflect the difficulty of recruiting drug free manics during acute phase. One of the 3 studies reported an enhanced cortisol response to 5-hydroxytryptophan (5-HTP) challenge (Meltzer et al. 1984), whereas the other 2 found no differences in prolactin and/or cortisol release to fenfluramine (Yatham 1996) or buspirone (Yatham 1994) challenges between manic patients and healthy controls.

Sumatriptan is a novel 5-HT1D receptor agonist used in treating acute migraine (Fowler et al. 1991). When given subcutaneously in normal volunteers, it increases growth hormone $(\mathrm{GH})$ release significantly without al- 
tering the release of other hormones such as prolactin, cortisol, or adrenocorticotrophin (ACTH) (Franceschini et al. 1994). GH levels peak at 30 to 60 minutes after sumatriptan injection, and return to baseline after 120 minutes (Franceschini et al. 1994). The purpose of this study was to compare sumatriptan induced GH release in patients with major depression or acute mania, and healthy controls.

\section{METHODS}

A total of 21 patients (13 with acute unipolar major depression and 8 with acute mania) and twelve normal controls were recruited. Of these, 3 healthy controls and 3 depressed patients had baseline GH levels above 5 $\mu \mathrm{g} / \mathrm{L}$, and were excluded from the analysis because, after a GH secretory episode, the pituitary is relatively refractory (Vance et al. 1985). The subjects were physically healthy and gave written informed consent for participation in the study. The DSM-1V diagnosis of major depressive disorder or bipolar disorder-current episode mania, was made by the consensus of the research team using the information generated from a clinical interview by a psychiatrist, and a structured clinical interview for DSM-111-R diagnosis (SCID) performed by a research assistant. Those that met criteria for other Axis 1 diagnoses, substance or alcohol abuse were excluded. The healthy controls had no lifetime history of psychiatric illness as determined by SCIDnon-patient version. The severity of depressive symptoms was assessed by the Hamilton rating scale for depression (HAM-D 21 item) (Hamilton 1960), and manic symptoms were assessed by the Young mania rating scale (Young et al. 1978). Patients with depression had a mean 21 item HAM-D score of $25.6 \pm 5.56$, whereas manic patients had a mean score of $32.75 \pm 5.23$ on Young mania rating scale. All study subjects except one manic patient were drug free for at least 10 days, with the exception of lorazepam prn, (mean dose received was less than $0.5 \mathrm{mg}$ per day). None of the subjects had received fluoxetine in the preceding 6 months. The testing was conducted at the Mood disorders clinical research unit. Subjects having fasted since midnight presented for testing between 7.30 and 8.00 AM. An indwelling intravenous catheter was inserted in a forearm vein at $8 \mathrm{AM}$ and subjects were allowed to rest but not sleep, smoke, or eat. The blood for baseline GH was obtained at $9.00 \mathrm{AM}$ (time 0 ) and $6 \mathrm{mg}$ of sumatriptan were given subcutaneously at this time. Further bloods were obtained at 30 minute intervals during the next 2 hours. The blood samples were placed on ice until all the samples were obtained for each subject. The samples were centrifuged, serum separated, and stored at $-70 \mathrm{C}$ for assay at a later time. Subjects rated at baseline, 30,
60,90 , and 120 minutes on $10 \mathrm{~cm}$ visual analogue scales (VAS) on the following items: least/most nauseated, best/worst concentration, and least/most drowsiness.

GH was assayed by Quantitope HGH Radioimmunoassay (Kallestad diagnostics). The samples were assayed blind to the diagnostic status of subjects. In addition, all samples from each subject were assayed in the same batch. The sensitivity of GH assay was $0.2 \mu \mathrm{g} / \mathrm{L}$. The intra-assay coefficients for $\mathrm{GH}$ were $6.8 \%, 5 \%$, and $9.1 \%$ for $\mathrm{GH}$ pools of $2.5 \mu \mathrm{g} / \mathrm{L}, 5.4 \mu \mathrm{g} / \mathrm{L}, 35.2 \mu \mathrm{g} / \mathrm{L}$ respectively. The interassay coefficients of variation were $10.8 \%$ for GH pool of $2.6 \mu \mathrm{g} / \mathrm{L}, 6.6 \%$ for $\mathrm{GH}$ pool of 5.8 $\mu \mathrm{g} / \mathrm{L}$, and $5.7 \%$ for $\mathrm{GH}$ pool of $11.3 \mu \mathrm{g} / \mathrm{L}$.

An analysis of variance (ANOVA) with repeated measures was used to compare differences in sumatriptaninduced $\mathrm{GH}$ release among patients with depression or mania, and healthy controls. The $\Delta \mathrm{GH}$ (peak minus baseline $\mathrm{GH}$ value) levels among the three groups were compared using Kruskal-Wallis test, and post-hoc analysis was carried out using Mann-Whitney test. Chisquare and Kruskal-Wallis tests were used, to compute the differences in sex and $\Delta$ VAS (peak minus baseline values) scores among the three groups. The correlations between $\Delta \mathrm{GH}$ and HAM-D21, $\Delta \mathrm{GH}$ and the Young mania scale scores, and $\Delta \mathrm{GH}$ levels and $\Delta$ VAS scores were computed with Pearson's and Spearman's correlation tests.

\section{RESULTS}

The age, sex, and baseline and peak GH levels, for the 27 study subjects, are presented in Table 1 . There was no difference in age (depressed patients $=4.5 .7 \pm 9.53$, manic patients $=42.62 \pm 13.39$, healthy controls $=$ $39.33 \pm 11.9$; one was ANOVA: $F=0.74, d f=2,24, p=$ 0.48 ), or sex (Chi-Square test, $\chi^{2}=2.90, d f=2, p=0.23$ ) among the three diagnostic groups.

The $\mathrm{GH}$ levels during baseline and at various time points, following sumatripan administration, are plotted in Figure 1. A one way ANOVA comparing baseline GH levels in patients with major depression or mania, and healthy controls showed no differences among the three groups $(F=0.37, d f=2,24, p=.68)$. The GH levels in the three groups, following sumatriptan administration, were compared using ANOVA with repeated measures which showed a main effect for time ( $F=$ 12.7, $d f=4,96, p<.001$ ) and for group by time interaction $(F=2.01, d f=8,96, p=.05)$, but no main effect for group ( $F=2.01, d f=2,24, p=0.15$ ). When GH levels in patients with major depression, were compared with GH levels in healthy controls, ANOVA showed a group by time interaction effect $(F=4.10, d f=4,68, p<.005)$, as well as a trend for a group effect $(F=3.80, d f=1,17$, $p<.06)$, but no group by time interaction $(F=0.47, d f=$ $4,60, p=.76)$ or group effect was noted when manic pa- 
Table 1. Demographic and Hormonal Data for Patients with Depression or Mania, and Healthy Controls

\begin{tabular}{|c|c|c|c|c|}
\hline & $\begin{array}{c}\text { Age } \\
\text { (years) }\end{array}$ & Sex & $\begin{array}{c}\text { Baseline GH } \\
\text { (uG/L) }\end{array}$ & $\begin{array}{c}\text { Peak GH } \\
(\text { uG/L) }\end{array}$ \\
\hline \multicolumn{5}{|l|}{ Depression } \\
\hline 1 & 59 & Female & 1.2 & 1.4 \\
\hline 2 & 60 & Male & 2.6 & 1.6 \\
\hline 3 & 51 & Male & 1.4 & 2.6 \\
\hline 4 & 41 & Female & 1.4 & 3.1 \\
\hline 5 & 44 & Female & 1.7 & 2.5 \\
\hline 6 & 39 & Female & 1.4 & 1.7 \\
\hline 7 & 49 & Female & 2.7 & 3.6 \\
\hline 8 & 48 & Female & 3.6 & 3.3 \\
\hline 9 & 34 & Male & 0.6 & 0.8 \\
\hline 10 & 33 & Male & 3.7 & 3.1 \\
\hline Mean $\pm S D$ & $45.8 \pm 9.3$ & - & $2.03 \pm 1.05$ & $2.37 \pm 0.94$ \\
\hline \multicolumn{5}{|l|}{ Mania } \\
\hline 1 & 32 & Female & 1.0 & 6.2 \\
\hline 2 & 44 & Female & 0.7 & 8.1 \\
\hline 3 & 49 & Female & 0.6 & 0.9 \\
\hline 4 & 24 & Female & 1.1 & 1.7 \\
\hline 5 & 66 & Female & 1.4 & 1.7 \\
\hline 6 & 33 & Male & 1.0 & 1.0 \\
\hline 7 & 40 & Female & 4.1 & 3.7 \\
\hline 8 & 53 & Female & 3.4 & 6.6 \\
\hline Mean $\pm S D$ & $42.6 \pm 13.3$ & - & $1.66 \pm 1.32$ & $3.66 \pm 2.92$ \\
\hline \multicolumn{5}{|c|}{ Healthy controls } \\
\hline 1 & 47 & Female & 1.9 & 4.7 \\
\hline 2 & 52 & Female & 1.2 & 3.1 \\
\hline 3 & 39 & Female & 1.3 & 7.3 \\
\hline 4 & 23 & Female & 1.3 & 3.0 \\
\hline 5 & 49 & Female & 1.7 & 1.7 \\
\hline 6 & 44 & Female & 2.0 & 3.1 \\
\hline 7 & 23 & Female & 2.2 & 10.2 \\
\hline 8 & 27 & Female & 2.3 & 10.6 \\
\hline 9 & 50 & Male & 1.5 & 2.0 \\
\hline Mean $\pm S D$ & $39.3 \pm 11.9$ & - & $1.71 \pm 0.41$ & $5.07 \pm 3.44$ \\
\hline
\end{tabular}

tients were compared with healthy controls $(F=1.30$, $d f=1,15, p=.27$ ).

Kruskal-Wallis test was used to compare the differences in $\Delta \mathrm{GH}$ levels among the three groups $\left(\chi^{2}=6.22\right.$, $d f=2, p<.04)$. Post-hoc comparisons were made with Mann-Whitney test which showed a significant difference between patients with major depression and healthy controls (Mann-Whitney $U=13.5, Z=-2.57$, $p<.008$ ), but not between manic patients and healthy controls (Mann-Whitney $U=22.5, Z=-1.30, p=.20$ ). There were, however, no significant correlations between $\Delta$ GH levels and HAM-D 21 item scores, or between $\Delta \mathrm{GH}$ levels and scores on the Young mania rating scale.

For behavioural measure, $\Delta$ VAS scores for nausea, concentration and drowsiness were calculated by subtracting baseline values from peak values, and analyzed by Kruskal - Wallis test. There were no differences in $\Delta$ VAS scores of nausea $\left(\chi^{2}=0.97, d f=2, p=.61\right)$, concentration $\left(\chi^{2}=0.27, d f=2, p=.87\right)$, or drowsiness $\left(\chi^{2}=4.73, d f=2, p=.09\right)$ among the three diagnostic groups. sumatriptan was in general well tolerated by all three groups. There was no correlation between $\Delta \mathrm{GH}$ levels and $\Delta$ VAS scores of nausea, concentration, or drowsiness in any of the three diagnostic groups (data not shown).

\section{DISCUSSION}

To our knowledge, this is the first study that measured sumatriptan induced GH release in patients with major depression or mania. The results indicated that patients with major depression had blunted GH release compared to healthy controls, whereas GH release in manic patients was not different from healthy controls.

GH responses to other 5-HT challenges such as L-tryptophan (Cowen and Charig 1987) and m-chlorophenylpiperazine (Anand et al. 1995) have been reported to be blunted in major depression. The finding of a 


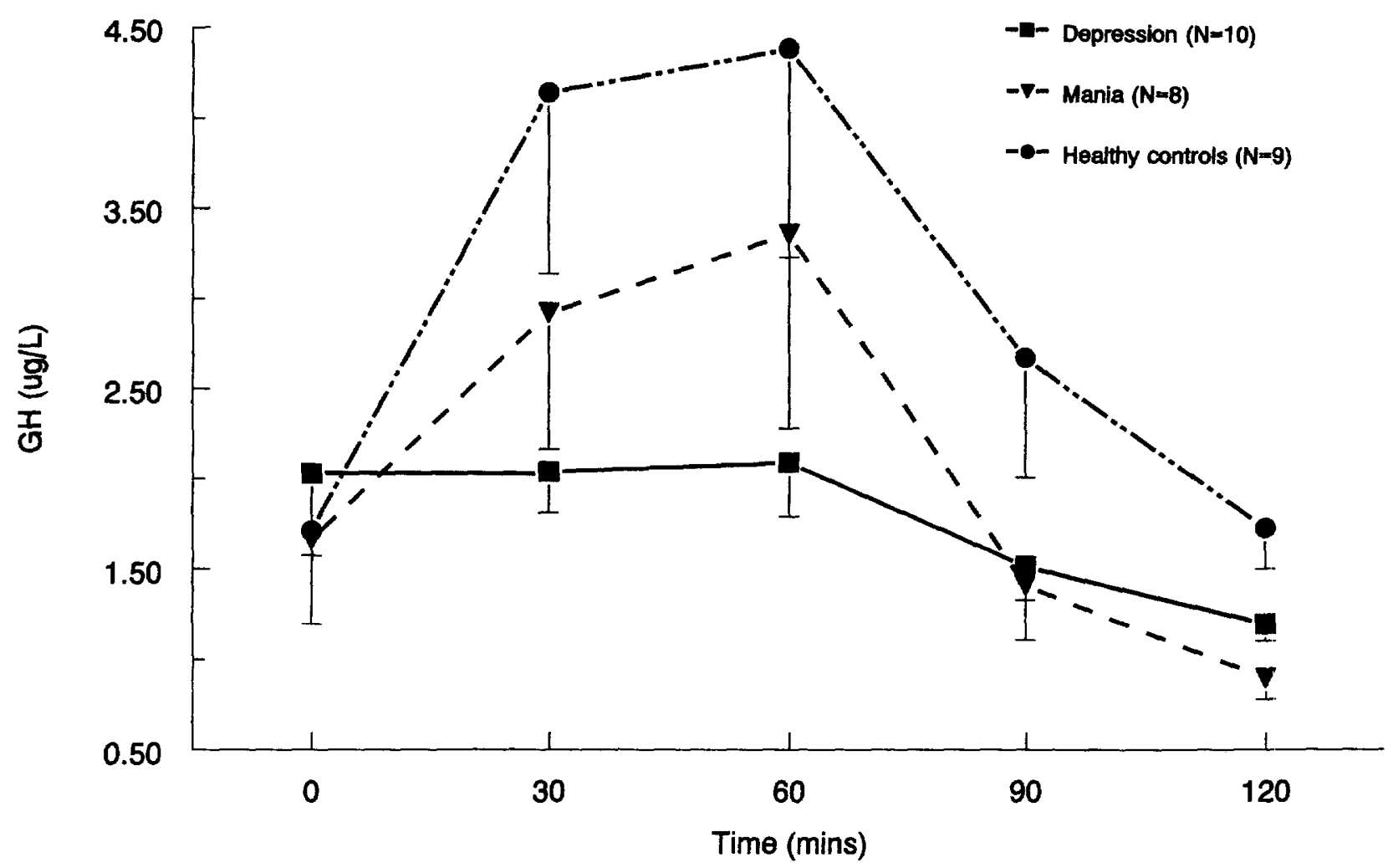

Figure 1. Growth hormone (mean $\pm S E M)$ responses to sumatriptan in patients with major depression $(N=10)$ or mania $(N=8)$, and healthy controls $(N=9)$.

blunted GH release to sumatriptan in depressed patients in this study, thus is in agreement with previous studies, providing further support for 5-HT dysfunction in major depression. Sumatriptan is a selective 5-HT1 agonist with no affinity for other 5-HTergic, dopaminergic, adrenergic, or muscarinergic receptors (Schoeffter et al. 1989; Humphrey et al. 1991). Within the 5-HT1 receptor family, it binds with 4 to 20 fold higher affinity to 5-HT1D receptors over 5-HT1A receptors (Schoeffter et al. 1989; Humphrey et al. 1991). This would suggest that sumatriptan induces GH release by stimulating 5-HT1D receptors, although the role of $5-\mathrm{HT} 1 \mathrm{~A}$ receptors cannot be excluded. Other studies assessing 5-HT1A responsivity in depressed patients have yielded conflicting results. For instance, buspirone induced GH release, which is considered to be mediated by 5-HT1A receptors (Anderson and Cowen 1992), was unaltered in depressed patients compared to normal controls (Cowen et al. 1994), whereas cortisol and ACTH release evoked by ipsapirone (also mediated by 5 -HT1A receptors) was blunted (Lesch et al. 1990). A further study in healthy volunteers assessing the effects of pindolol, a $\beta$-blocker with 5-HT1A antagonistic properties (Hamon et al. 1987), on sumatriptan induced GH release might help to resolve this issue.

The release of GH from the pituitary is regulated by the stimulating effects of $\mathrm{GH}$ releasing hormone (GHRH)
(Sawchenko et al. 1985) and the inhibiting effects of somatostatin (Urman et al. 1995). 5-HT does not stimulate GH from the pituitary in vitro (Kato et al. 1980). There is evidence that 5-HT increases release of GHRH (Murakami et al. 1986) but it has no effect on somatostatin (Chihara et al. 1979). Therefore, it is likely that 5-HT agonists evoke $\mathrm{GH}$ release from the pituitary by increasing the release of GHRH. A blunted GH release has been reported not only with 5-HT challenges but also with adrenergic drugs such as clonidine and desipramine (Checkley et al. 1981; Dinan and Barry 1990) and dopaminergic drugs, such as apomorphine (Ansseau et al. 1988) in depressed patients. This raises the question whether there is a defect in GH secretion at the pituitary level in patients with major depression, perhaps due to an alteration in sensitivity of pituitary somatotrophs. Studies that assessed pituitary somatotroph responsivity by measuring GH release to GHRH challenge in depressed patients have yielded conflicting results, with some showing a normal release and others a decreased release, in comparison to controls (Krishnan et al. 1988; Thomas et al. 1989; Leach et al. 1987). Further studies are clearly needed to resolve this issue.

In regards to manic patients, the $\mathrm{GH}$ responses were not different than the ones obtained from healthy controls. Since we studied only 8 manic patients we cannot exclude the possibility of a type 2 error. $\mathrm{GH}$ responses 
to 5-HT challenges have not been assessed in manic patients, in any of the previous investigations. However, of the 3 previous neuroendocrine studies that measured prolactin and/or cortisol to fenfluramine (Yatham 1996), buspirone (Yatham 1994), and 5-hydroxytrptophan (Meltzer et al 1984) challenges, 2 reported no differences in hormone release (Yatham 1994; Yatham 1996), whereas the third found enhanced responses (Meltzer et al. 1984) in manics compared to controls. The $\mathrm{GH}$ responses in manics, in the present study, were somewhat lower, but not significantly different, from GH responses in healthy controls. The results of this investigation, therefore, are in agreement with 2 previous studies, providing little support for 5-HT dysfunction in this condition.

In summary, the results of this study showed blunted GH release to sumatriptan challenge in depression, but not in mania. These findings, therefore, provide support for 5HT dysfunction in depression, but not in mania.

\section{REFERENCES}

Anand A, Charney DS, Delgado PL, McDougal CJ, Heninger GR, Price LH (1994): Neuroendocrine and behavioural responses to intravenous $\mathrm{m}$-Chlorophenylpiperazine (mCPP) in depressed patients and healthy comparison subjects. Am J Psychiatry 151:1626-1630

Anderson IM, Cowen PJ (1992): Effect of pindolol on endocrine and temperature responses to buspirone in healthy volunleers. Psychopharmacology 106:428-432

Ansseau M, von Frenckell R, Cerfontaine JL, Papart P, Frank G, Timsit-Berthier M, Geenen V, Legros JJ (1988): Blunted response of growth hormone to clonidine and apomorphine in endogenous depression. Br J Psychiatry 153:65-71

Checkley SA, Slade AP, Shur E (1981): Growth hormone and other responses to clonidine in patients with endogenous depression. Br J Psychiatry 138:51-55

Chihara K, Arimura A, Schally AV (1979): Effect of intraventricular injection of dopamine, norepinephrine, acetylcholine, and 5-hydroxytryptamine on immunoreactive somatostatin release into rat hypophyseal portal blood. Endocrinology 104:1656-1662

Cowen PJ, Charig EM (1987): Neuroendocrine responses to intravenous tryptophan in major depression. Arch Gen Psychiatry 44:958-966

Cowen PJ, Power AC, Ware CJ, Anderson IM (1994): 5-HT1A receptor sensitivity in major depression: A neuroendocrine study with buspirone. Br J Psychiatry 164:372-379

Dinan TG, Barry S (1990): Responses of growth hormone to desipramine in endogenous and non-endogenous depression. Br J Psychiatry 156:680-684

Fowler PA, Lacey LF, Thomas M, Keene ON, Tanner RJN, Baber NS (1991): The clinical pharmacology, pharmacokinetics and metabolism of sumatriptan. Eur Neurol 31:291-294

Franceschini R, Cataldi A, Garibaldi P, Scordamaniglia A, Barreca T, Rolandi E (1994): The effects of sumatriptan on pituitary secretion in man. Newopharmocology 33 : 235-239

Golden RN, Ekstrom D, Brown TM, Ruegg R, Evans DL, Haggerty Jr JJ, Garbutt JC, Pedersen CA, Mason GA, Browne J, Carson SW (1992): Neuroendocrine effects of intravenous clomipramine in depressed patients and healthy subjects. Am J Psychiatry 149:1168-1175

Hamilton M (1960): A rating scale for depression. J Neurol, Neurosurg, Psychiat 23:56-62

Hamon M, Emerit B, El Mestikawy S, Verge D, Daval G, Marquet A, Gozcan H (1987): Pharmacological, biochemical and functional properties of 5-HT1A receptor binding sites labeled by $\left.{ }^{3} \mathrm{H}\right] 8$-hydroxy-2-(di-n-propylamino) tetralin in the rat brain. In CT Dourish, $\mathrm{S}$ Ahlenius, $\mathrm{PH}$ Huston (eds), Brain 5-HT1A receptors. Chichester, Horwood, pp 34-51

Humphrey PPA, Feniuk W, Marriott AS, Tanner RJN, Jackson MR, Tucker ML (1991): Preclinical studies on the anti-migraine drug, sumatriptan. Eur Neurol 31:282-290

Kato Y, Matsushita N, Katakami H, Imura H (1980): Brain serotonin and the secretion of prolactin and growth hormone. Clin Endocrinol (Tokyo) 28:625

Krishnan KR, Manepalli AN, Ritchie JC, Rayasam K, Melville ML, Daugtry G, Thorner MO, Riviere JE, Vale WW, Nemeroff CB, Carrol BJ (1988): Growth hormonereleasing factor stimulation test in depression. Am J Psychiatry 145:90-92

Lesch KP, Laux G, Erb A, Pfuller H, Beckmann H (1987): Attenuated growth hormone response to growth hormone-releasing factor in major depressive disorder. Biol Psychiatry 22:1491-1495

Lesch KP, Mayer S, Disselkamp-Tietze J, Hoh A, Weismann M, Osterheider M, Schulte HM (1990): 5-HT1A receptor responsivity in unipolar depression: Evaluation of ipsapirone-induced $\mathrm{ACTH}$ and cortisol secretion in patients and controls. Biol Psychiatry 28:620-628

Meltzer HY, Umberkoman-Wiita B, Robertson A, Tricou BJ, Lowy M, Perline R (1984): Effect of 5-hydroxytryptophan on serum cortisol levels in major affective disorders. Arch Gen Psychiatry 41:366-374

Murakami Y, Kato Y, Kabayama Y, Tojo K, Inque T, Imura H (1986): Involvement of growth hormone (GH)-releasing factor in $\mathrm{GH}$ secretion induced by serotonergic mechanisms in conscious rats. Endocrinology 119(3):1089-1092

O'Keane V, Dinan TG (1991): Prolactin and cortisol responses to d-Fenfluramine in major depression: Evidence for diminished responsivity of central serotonergic function. Am J Psychiatry 148:1009-1015

Sawchenko PE, Swanson LW, Rivier J, Valer WW (1985): The distribution of growth-hormone-releasing factor (GRF) immunoreactivity in the central nervous system of the rat: An immunohistochemistry study using antisera directed against rat hypothalamic GRF. J Compr Neurol 237:100-115

Schoeffter P, Hoyer D (1989): How selective is GR 43175? Interactions with functional 5-HT1A, 5-HT1B, 5-HT1C and 5-HT1D receptors. Naunyn Schmiedeberg's Arch Pharmacol 340:135-138

Thomas R, Beer R, Harris B, John R, Scalon N (1989): GH responses to growth hormone releasing factor in depression. J Affect Disord 16:133-137 
Urman S, Kaler L, Critchlow V (1985): Effects of hypothalamic periventricular lesions on pulsatile growth hormone secretion. Neuroendocrinology 41:357-362

Vance ML, Kaiser DL, Evans WS, Thorner MO, Furlanetto R, Rivier J, Vale W, Perisutti G, Frohman LA (1985): Evidence for a limited growth hormone (GH)-releasing hormone (GHRH)-releasable quantity of GH: effects of 6-hour infusions of GHRH on GH secretion in normal man. J Clin Endocrinol Metab 60:370-375
Yatham LN, Steiner M (1993): Neuroendocrine probes of serotonergic function: A critical review. Life Sci. 53:447-463

Yatham LN (1994): Buspirone induced prolactin release in mania. Biol Psychiatry 35:553-556

Yatham LN (1996): Prolactin and Cortisol responses to fenfluramine challenge in mania. Biol Psychiattry 39:285-288

Young RC, Biggs JT, Ziegler VE, Meyer DA (1978): A rating scale for mania: Reliability, validity and sensitivity. $\mathrm{Br} \mathrm{J}$ Psychiatry 133:429-435 